\title{
A landmark in cooperation
}

\section{Mickey M. Karram • Christopher R. Chapple}

Published online: 25 November 2009

(C) The International Urogynecological Association 2009

It is with great pleasure that the editorial teams of the journals Neurourology \& Urodynamics and International Urogynaecology Journal, representing the societies ICS, IUGA and SUFU, are able to publish a joint report on suggested terminology for female pelvic floor dysfunction.

This is a landmark development representing the first joint initiative between these two journals and their respective societies. The aim of this impressive report was to develop a coherent and user-friendly document with the intention of facilitating accurate communication for research and clinical purposes.

We certainly would welcome any comments on this report, which has been through extensive peer review, in the form of letters and communications to the journals. We both hope that this report will stimulate further collaboration between our respective societies and journals in our continued pursuit of a better understanding of female pelvic floor dysfunction.

\footnotetext{
M. M. Karram ( $\square)$

Director of Urogynecology, The Christ Hospital,

2123 Auburn Ave, Suite 307,

Cincinnati, OH 45219, USA

e-mail: mickey_karram@trihealth.com

C. R. Chapple

Department of Urology, Royal Hallamshire Hospital,

Glossop Road,

Sheffield, UK

e-mail: c.r.chapple@shef.ac.uk
} 